\title{
Labirinto Laban
}

\author{
Cibele Sastre \\ Universidade Federal do Rio Grande do Sul - UFRGS, Porto Alegre/RS, Brasil \\ E-mail: cibele.sastre@gmail.com
}

\begin{abstract}
Este artigo propõe uma relação entre arte e vida, articulando eventos da vida privada de Rudolf Laban com a criação de seus referenciais para os estudos da Arte do Movimento, hoje disseminados em diferentes vertentes e centros de estudo. Reúne alguns aspectos de sua biografia a partir de dois principais referenciais internacionais - Valerie Preston-Dunlop (UK) e Karen Bradley (USA) - duas autoras respectivamente ligadas a centros de formação do legado labaniano - O Trinity Laban e o LIMS: Laban/Bartenieff Institute of Movement Studies -, que trazem intensa pesquisa sobre a vida e a obra de Rudolf Laban. A partir da compilação de informações menos visitadas pelos textos acadêmicos biográficos, é possível acessar rastros de movimentos labirínticos multidimensionais relacionais e as propulsões em que Laban flui, visando dar acesso a obras não traduzidas para o português. Entre a partilha contingente, e suas (des)continuidades, vemos um constante retorno a si mesmo em outros corpos, espaços e tempos.
\end{abstract}

\section{Palavras-chave}

Rudolf Laban. Arte do Movimento. Arte-Vida.
This article proposes a relationship between art and life by articulating events from Laban's private life with the creation of his references for studies in the Art of Movement, which today circulate through different areas and study centers. It brings together some aspects of Laban's biography by two international references - Valerie Preston-Dunlop (UK) and Karen Bradley (USA) - two authors respectively connected to training centers of the Laban legacy - Trinity Laban (UK) and LIMS: Laban/Bartenieff Institute of Movement Studies (USA) - that perform intense research on the life and work of Rudolf Laban. Based on the compilation of information less frequented by academic biographical texts, it is possible to access traces of relational multidimensional labyrinthine movements and the propulsions in which Laban flows, in order to give access to works which have not been translated into Portuguese. Between the contingent sharing, and its (dis)continuities, we see a constant return to itself in others bodies, spaces and times.

Rudolf Laban. Art of Movement. Art-Life. 


\section{Introdução}

Ao falarmos de Rudolf Laban (1879-1958) e seu legado infinito, propulsionado por suas formas de conferir sentido ao movimento como elemento da comunicação humana, arbitrariamente é necessário fazer escolhas. Neste momento, vou entretecer narrativas que apresentam aspectos desta figura camaleoa de percursos não lineares e discursos corporalmente articulados. Qualquer que seja a fonte da biografia de Laban, ao adentrarmos no seu universo cotidiano, identificamos que esse 'teórico' da dança moderna alemã, como muitos costumam defini-lo, é uma pessoa com intensa curiosidade pelos mistérios da alma humana e sua expressão na Arte. Sua genialidade emerge de um labirinto psicoafetivo em meio a eventos contingentes ao turbulento início do século XX. As decisões tomadas ao longo de sua vida proporcionam alguns rastros que nos aproximam de suas criações, rupturas e produção de conhecimento. Assim, o campo da dança se fortalece por meio de um legado que compreende a corporificação (embodiment) de inúmeros experimentos oriundos do que chamou de Arte do Movimento.

Seu legado constitui uma 'propriedade intelectual' da qual ele nunca se apropriou de fato, segundo Karen Bradley (2009) por ter partilhado suas reflexões com seus pares. Considera-se hoje que ele foi um analista em movimento, ampliando à interlocução interpessoal o discurso corporal e gráfico, e suas respectivas produções de sentido. Criou um sistema de análise qualitativo expresso em termos artísticos (o movimento dançado e seu registro iconográfico e poético) e científicos, visando integrar a dança e sua efemeridade aos registros acadêmicos das demais artes, para ampliar o círculo de sua abrangência. "Como um verdadeito visionário, a vida para ele foi uma longa improvisação. Ele se descrevia como uma salamandra, [...] - olhos se precipitando para enxergar tudo, rápido, avançando constantemente" (BRADLEY, 2009, p. 1), enquanto era descrito como "um gênio, manipulador e um 'mulherisador' ', o que demonstra facetas deste homem complexo; um homem sem um plano, mas um homem com propósito" (BRADLEY, 2009, p. 1). Esta autora o descreve como ingênuo, esperto, aberto a novas possibilidades e pontos de vista, mas por vezes dogmático, também. Suas âncoras familiares produziram liberdade, autonomia e singularidade àquele que, num dado momento, poderia ter se tornado militar na Bratislava do século XIX, como nos mostra sua aluna inglesa Valerie Preston-Dunlop: "[...] sua pequena permanência na escola de cadetes confirmou sua já profunda ansiedade de que as máquinas dominariam a alma humana em profundo detrimento da cultura humana" (PRESTON-DUNLOP, 1998, p. 6).

As palavras que se seguem são parte da minha leitura sobre duas fontes biográficas de Laban não traduzidas para o português, até o momento, sob meu filtro transcriador': Rudolf Laban, an extraordinary life de Valery Preston-Dunlop (1998) e Rudolf Laban de Karen K. Bradley (2009). A escolha das fontes oferece duas perspectivas, dois olhares de autoras diretamente ligadas aos centros de formação internacional de referência histórica, nos dois países sediadores (Reino Unido e Estados Unidos) que cultivam diferentes aproximações com a Arte do Movimento. Também, minha experiência de formação e trajetória como especialista nos estudos de movimento Laban/Bartenieff $\left(\mathrm{CMA}^{3}\right)$, e o contato

1 Womanizer no original, como neologismo para humanizador (humanizer) no/do feminino, além de evocar também sua tendência a manter relacionamentos não convencionais com mulheres.

2 Transcriação é um conceito elaborado pelo escritor, poeta e tradutor Haroldo de Campos (1929-2003) para exprimir o exercício de transliteração de um tradutor. Também entendido como transficcionalização, considerando a recontextualização operante na leitura do receptor e a fiç̧ão de segundo grau, "que reprocessa, metalinguísticamente, o fictício do poema". (TAPIA, e NÓBREGA, 2013) O uso do conceito de transcriação é também usado operacionalmente em pesquisas em arte, como oportunidade de uma criação em si. (ADAMS, CARDOSO, et all., 2019)

3 Certified Movement Analyst pelo Laban| Bartenieff Institute of Movement Studies de NY, contemplada com a Bolsa virtuose do Ministério da Cultura do Brasil. 
com profissionais nacionais e internacionais de referência em tais estudos, guiam as lentes com as quais este texto é escrito. São dados que nos ajudam a cartografar parte da vida deste homem de improvisos geniais, seus propósitos e caminhos intuitivos, e que nos permitem inferir sobre seu tempo e contexto.

Valerie Preston-Dunlop formou-se com Laban no estúdio da Arte do Movimento, que em 1970 ascendeu para o título de Laban Center for Movement and Dance e, em 2002, uniu-se à Trinity College of Music, tornando-se Trinity Laban Conservatoire for Music and Dance. Preston-Dunlop pesquisou extensivamente a vida e a obra de Rudolf Laban, foi diretora do Laban Center em várias gestões, remontou seus trabalhos coreográficos e tem uma extensa produção audiovisual e intelectual sobre esse legado, tendo sido responsável por reconhecer uma pós-graduação em nível de mestrado na formação do Laban Center.

Karen Bradley é vice presidente do Laban|Bartenieff Institute of Movement Studies (LIMS) em Nova lorque, fundado por Irmgard Bartenieff (19001981), e diretora de pesquisas do LIMS. É professora emérita associada da School of Theatre, Dance and Performance Studies da Universidade de Mariland, atualmente pesquisando padrões de ondas cerebrais em qualidades de movimento expressivo particulares, junto com a equipe do Dr. José Contreras Vidal da Universidade de Houston. Trabalha na aproximação dos Estudos do Movimento Laban| Bartenieff -LBMS ${ }^{4}$ e neurociência.

Um labirinto oferece muitos percursos e a ideia inicial de desorientação. Razão e intuição são solicitadas, convidadas ao exercício da imaginação do fora e da observação do dentro, em busca de sentidos como orientação espacial e como significados para seguir 'em frente'. Assim como as imagens do holandês M. C. Escher (1898-1972), a Arte do Movimento de Laban nos oferece uma possível flexibilização a partir de uma perspectiva relacional com os eventos da vida, produzindo mudanças materiais e filosóficas. Os desafios podem operar como trampolins para ní-

4 Laban| Bartenieff Movement Studies. veis altos, mesmo que seguidos de quedas bruscas e silêncios, e como propulsões de qualidades dinâmicas e expressivas de movimentos. Sobre esse labirinto multidimensional e espiralado, o jogo de portas ou paredes que se abrem opera em sincronia com os eventos e com o corpo-vivo-em-movimento (MIRANDA, 2008) que produz o conhecimento labaniano. Assim surge o desejo de compartilhar alguns aspectos da vida deste homem que, mesmo quando desorientado, produzia conhecimento sobre mais um elemento de seu legado, positivando polarizações.

\section{Mobilidade e magia}

"Nunca se sabe de antemão como alguém vai aprender - que amores tornam alguém bom em latim, por meio de que encontros se é filósofo, em que dicionários se aprende a pensar" (DELEUZE, 2006, p. 238). Laban foi criado pelos avós maternos, em uma família de 'pessoas importantes', entre médicos, diplomatas, e oficiais do exército - seu pai e sua mãe serviam o exército húngaro. Um tio, considerado o estranho da família, foi sua inspiração. Laban adorava ficar com ele na infância, que viveu entre os avós e tios, mais do que com os pais. Quando possível, circulava com seu pai em cidades do Leste europeu para onde era designado. Assim, teve muitos encontros com diferentes culturas e suas danças, muitas vezes, religiosas. Conheceu dessa forma os Dervishes e a irmandade Sufi, que rezava em movimento, girando até um estado de transe e imunizando o corpo contra feridas e ataques com tacos, ou pontas de espadas, floretes, estoque. "Essa magia da dança, esse poder do movimento sobre o homem, foi profundamente impressionante para o jovem Laban. Ele via isso como a conquista das forças da natureza por meio da dança" (PRESTON-DUNLOP, 1998, p. 3).

Persuadido pelo pai a estudar na academia militar de Wiener Neustadt para treinamento de jovens oficiais, foi descrito como alguém que tinha habilidade com atividades físicas, mas não com a língua Alemã. Decidiu tornar-se artista ao perceber a ameaça que esta escola trazia para suas ideias humanistas. 
Precursor de um pensamento integrador entre corpo, mente e espírito, "seu desejo de levar uma vida de artista estava longe de um desejo egocêntrico de enterrar sua alma na pintura, mas, em vez disso, um desafio auto-imposto de proteger a dimensão espiritual da vida contra o efeito fulminante desta industrialização" (PRESTON-DUNLOP, 1998, p. 7).

Por sua paixão pela dança e por tentar persuadir seus colegas a participarem de um festival, o garoto Laban foi transgressor. No ano em que passou fora da escola, aos 14, produziu pequenos sketches de teatro para ele, como diversão, e circulava pelos bastidores do teatro municipal, enriquecendo sua auto-educação. Começou a ajudar com pequenos trabalhos no teatro municipal da Bratislava e aprendeu design, decore e confecção de figurino, familiarizando-se com o repertório musical da casa. Inicialmente de modo extra-oficial, ao final de um ano de colaborações, foi permitida sua atuação oficial no teatro, que incluía apresentar suas performances dramáticas para governantes. Sendo seu pai, neste período, marechal e governador das províncias turcas ocupadas (Bósnia e Herzegovina), ele teve a oportunidade de representar seus trabalhos para o governador da Bratislava. Ele também fundou, neste período, um clube jovem de teatro (PRESTON-DUNLOP, 1998).

Visitante frequente de Viena, herdeiro de um título de nobreza que seu pai recebeu em final de carreira, Rudolf Von Laban conviveu com um contraste cultural de valores em um tempo de intensas transformações. Foi contemporâneo das proposições de Sigmund Freud (1856-1939) e seus colaboradores, de Arnold Schönberg (1874-1951), Vasili Kandinsky (1866-1944), Émile Jaques-Dalcroze (1865-1950), Bess Mensendieck (1864-1957) e Rudolf Bode (18811971), para citar alguns dos influentes em seus pensamentos. Junto com a reverberação da morte de deus em Nietzsche, viu a emergência do conceito de psiquê e de novos comportamentos ligados a sexo, sexualidade e erotismo, e pensamentos relativos às divisões do ser humano entre mente, corpo e alma.
Laban viu certezas éticas sendo desafiadas em Viena, enquanto via valores tradicionais mantidos severamente em vários círculos étnicos de Sarajevo. Via a emancipação feminina em Viena, a capital mais ocidental do Império, em contraste com a permanência do subjugo da mulher no leste. Essas discrepâncias eram o backgroud para o desenvolvimento de seu próprio senso de comportamento social e suas atitudes frente às mulheres e às crenças religiosas. $O$ suporte recebido dos avós e a visão avançada de sua mãe, junto com a rigidez tradicional de seu pai, formavam seu contexto familiar. (PRESTON-DUNLOP, 1998, p. 6).

Em 1900, casou-se com uma estudante de artes visuais de Hannover, Martha Fricke, com quem foi viver em Munique. Lá, estudaram por meios não tradicionais, sobretudo com o escultor e ceramista Hermann Obrist (1862-1927), considerado pioneiro na disseminação da Art Nouveau ${ }^{5}$ (Jugendstil) na Alemanha. Neste período, ecos de "suas experiências com os rituais sufi e sua imaginação vívida e o senso de parentesco com o mundo das plantas, dos animais e de forças inanimadas o tornaram um atento ouvinte de Obrist" (PRESTON-DUNLOP, 1998, p. 8). Preston-Dunlop também conta que somente mais tarde ele se ocupou do ocultismo, em Paris, mas que já era atento aos sinais de dois mundos: o mundo do silêncio e o da aventura. De acordo com o material de seus manuscritos, práticas e outras evidências, a autora afirma que não há dúvidas de que Laban operou frequentemente entre os mundos espiritual e material, e que um encontro espiritual ocorreu, possivelmente, entre ele e Obrist naquele período. É quando ele "planta as sementes fundamentais para a dança absoluta como a arte do movimento do corpo/alma" (PRESTON-DUNLOP, 1998, p. 9), em oposição a um código de dança homogeneizador de corpos.

Ele chegou em Paris num período iluminado, em que a luz elétrica estava dominando a modernidade, na virada do século. Lá conheceu Loie Fuller

5 Art Nouveau é um movimento artístico de renovação do modernismo, iniciado na França e na Bélgica entre o final do século XIX e o início do século XX, difundido na Europa com outros nomes. 
(1862-1928) $)^{6}$, justo quando ela estava se tornando famosa em Paris e no mundo, com experimentos entre ciência e arte, entre movimento, tecidos, luz e cor. Conheceu também Claude Monet (1840-1926), Auguste Rodin (1840-1917), Paul Gaugin (18481903), Paul Cézanne (1839-1906), e presenciou a ascensão de Henri Matisse (1869-1954) e do cubismo com Pablo Picasso (1881-1973) na boemia de Paris. Viveu a arte emergente da cidade em seu período de formação, mas não se sabe ao certo sobre o seu ingresso em alguma outra escola oficial, além da preparatória para a aprovação na Escola de Belas Artes, a Evening School, junto com sua esposa Martha. Exposições de obras arquitetônicas de Laban confirmam seus estudos, sendo sua obra-prima o projeto de um teatro circular para a dança. Nesse período, Laban tornou-se membro da organização de caráter mítico-filosófico Rosacruz, que tem por missão promover o auto aperfeiçoamento físico, psíquico e espiritual segundo princípios milenares que evocam poderes interiores, visando a plenitude de uma vida integral. Segundo Preston-Dunlop (1998), ele, junto a expoentes da arte parisiense, pareciam ter criado uma ordem rosacruciana própria. O conceito ideal de beleza ${ }^{7}$ da arte mística, cujos temas recorrentes eram lendas, mitos, alegorias, sonhos, paráfrases de poetas e lirismos, incluía a noção de harmonia como virtude a partir da Seção Áurea ${ }^{8} \mathrm{e}$, com ela, Michelangelo (1475-1564) e Leonardo Da

6 Para visualizar as transformações propostas por Fuller naquele período, sugiro assistir ao filme $A$ Dançarina, de Stéphanie Di Giusto, de 2016, protagonizado pela cantora e atriz francesa SoKo - Stephanie Sokolinski.

7 Trata-se de um conceito clássico de beleza construído a partir da proporção harmônica encontrada na natureza, tomando por base a seção áurea, também presente na proporção das partes de diferentes corpos vivos.

8 Seção Áurea é um cálculo matemático [expresso na equação $A: B=B:(A+B)]$ que expressa a relação recíproca entre duas partes não iguais de um todo, "em que a parte menor mantém a mesma proporção da parte maior, como a parte maior está para o todo [...]. A completa reciprocidade desta proporção nos impacta como particularmente harmônica e agradável, fato provado por muitos experimentos científicos desde o fim do século passado" (DOCZI, 1994, p. 2).
Vinci (1452-1519) eram reverenciados (PRESTON-DUNLOP, 1998). Tanto a Seção Áurea quanto os temas recorrentes dessa nova ordem tornam-se fundamentos no desenvolvimento da Arte do Movimento.

Em contato com o reino psíquico, que ele chamava de terra do silêncio (the land of silence), aprendeu técnicas de intensificação da energia interior, disparadas por meio da ativação do antrie $b^{9}$. Através dessas experiências, começou a modular a ideia de utilização das energias corporais em movimento e do fluxo de sua emanação, bem como a perceber o ritual como poderoso meio de internalização de ensinamentos. "Rituais operam como uma forma participativa de teatro, através da qual significados fundamentais podem ser sentidos, o movimento provê acesso a estes significados que são, de qualquer modo, não verbais" (PRESTON-DUNLOP, 1998, p. 12). A busca de Laban pelo trânsito entre os dois mundos (e as suas respectivas modulações na Arte do Movimento) incluiu estudos dedicados aos seus referenciais das Artes, da Dança, e de suas principais vivências como humanizador por meio do caminho espiritual. Ainda que muitos produzam críticas sobre a utilização direta de temas rosacrucianos em suas proposições teórico-práticas, a contribuição para o campo da dança tem sido inquestionável, bem como sua proposição genuína de articulação entre vida e arte (de inspiração nietzscheniana), que surgiu a partir de sua própria experiência. Segundo Karen Bradley,

Laban era altamente espiritualizado, mas ele não se filiou a nenhuma prática espiritual, ele não era um cultista ${ }^{10}$. Ele era atraído pelas práticas de expansão da percepção, mais do que por se deixar dominar pela magia de crenças não examinadas. Ele buscava expe-

9 Antrieb foi traduzido para o inglês como effort, e para o português como 'esforço', sobretudo nas traduções dos livros de Laban nos anos 1970. Fernandes (2006) o traduziu como 'expressividade' e, mais tarde, 'pulsão'. As palavras 'propulsão' e 'ímpeto' também a traduzem com efetividade, mas nas traduções brasileiras podemos encontrar diferentes termos para o que seria o equivalente aos estudos da eukinética.

10 A autora afirma que Laban não se tornou fiel a nenhuma ordem e que não frequentava cultos religiosos regularmente. 
rimentar as crenças de qualquer aspecto da sociedade e aplicar esta perspectiva em seu trabalho criativo. Ao fim, sua abertura foi parte de sua estética, um de seus muitos talentos, e informou, mais tarde, o desenvolvimento de suas teorias. (BRADLEY, 2009, p. 8).

Laban atravessou um profundo momento de depressão pela morte de sua esposa Martha, em 1907. Seu mundo interior o fez desaparecer e entregar as duas crianças para a mãe de sua esposa, deixando um vazio de referências sobre seu paradeiro por aproximadamente 3 anos - período em que voltou para a casa da família, onde, meses depois, enfrentou também a morte do pai, deixando-o sem recursos financeiros. Por fim, acabou se reerguendo em 1910, quando se casou com a cantora Maja Lederer, na Bratislava, e os dois mudaram-se para Munique, onde o artista, segundo Preston-Dunlop (1998) - com base no historiador Robin Lenman -, criou "um oásis de pensamento anti-autoritário e de fácil tolerância" (PRESTON-DUNLOP, 1998, p. 17). Seu idealismo enfrentava a sombra de seu falecido pai, uma vez que ele precisava se tornar responsável por sua vida financeira. Nesse período, o casal vivia com os trabalhos temporários de Laban, em sua maior parte voltados ao desenho, e com a colaboração de Maja, interrompida pelo nascimento de sua primeira filha, Johanna.

Entre 1910 e 1914, o casal apresentou performances de dança junto à efervescente cena artística de Munique, em que a dança tinha um grande espaço - contrastando com os emergentes Ballets Russos de Diaghilev"11, em Paris, onde "o chique e o chocante juntavam forças para as audiências das óperas, enquanto em Munique, simplicidade e cor-

11 Sergei Diaghilev (1872-1929) foi um grande empreendedor russo do ballet da virada do século $\mathrm{XX}$, um empresário artístico com visão internacional que popularizou e estreitou distâncias entre a tradição do ballet e as vanguardas europeias. Aproximou ícones das artes como Pablo Picasso, Henri Matisse, Jean Cocteau, Igor Stravinski, aos bailarinos e coreógrafos George Balanchine, Vaslav Nijinski, entre outros, mantendo os Ballets Russos de Diaghilev na França como companhia de dança ativa por 20 anos, entre 1909 e 1929. poreidade eram o ponto alto" (PRESTON-DUNLOP, 1998, p. 18). Uma Era espiritualista para a arte era o ponto alto nos círculos de artistas em Munique. Foi nessa época que Laban se aproximou do russo considerado pioneiro da arte abstrata, Vasili Kandinsky.

Kandinsky problematizava forma e cor através de uma relação de dependência da cor sobre a forma, mas não da forma sobre a cor. Também produzia o conceito de que "o próprio meio tem forças expressivas tornando obras chamadas pintura abstrata como plenas de sentido: o significado não-denotativo se refere ao espiritual e é tornado visível através das propriedades do meio" (PRESTON-DUNLOP, 1998, p. 20).

A troca com Kandinsky levou Laban a falar sobre a emergência do meio na dança, não pela eliminação da representação (que não era problema para ele nessa arte), mas pela ruptura de uma relação de dependência com a música e com o escopo de passos que constituem determinados vocabulários específicos. Suprimi-los seria o caminho para revelar o meio na dança - o que, de fato, poderia incluir um componente de relação muito forte entre a experiência corporal e espiritual, para o que ele tornou-se mais atento ao entrar em contato com as propostas emergentes do período.

Influências da Cultura Corporal (Korperkultur) de Bess Mensendieck, e da Eurítmica de Dalcroze e de Rudolf Bode, alimentadas pela crença na relação entre as dimensões física e espiritual do corpo, não eram suficientes para Laban, que estudava, neste período, as cartas de Noverre e os sistemas de notação de dança existentes. Quando convidado por Dalcroze a assistir um ensaio geral da abertura de sua escola, ainda que envaidecido por estar entre as celebridades da dança naquele contexto, Laban percebeu a necessidade de desatar a relação entre dança e música, que era fundamental para os estudos dalcrozianos (PRESTON-DUNLOP, 1998).

É incrivelmente interessante perceber o manancial de influências que Laban teve no início do século XX, sobretudo em Munique e em Paris, e como esse trend de arte que se constituía naquele período produziu ambientes profícuos para a experimentação da arte em sua plena interdisciplinaridade. 


\section{Impulsos mágicos: escola-colônia}

Em Ascona, cidade suíça localizada às margens do Lago Maggiore, mais precisamente no Monte Veritá, entre a Itália e a Suíça - local que se tornaria um refúgio para tantos artistas e intelectuais anarquistas, ele conheceu Mary Wigman (1886-1973), com quem estabeleceria uma parceria fundamental para a história da dança moderna na Alemanha. Laban foi convidado a dar aulas em Ascona numa escola de verão para as artes, que se tornou um laboratório a céu aberto para seus experimentos relacionais entre artes visuais, arquitetura e dança - no que foi também chamado de escola-colônia. Segundo Bradley (2009), ele não tinha a real dimensão da proposta política de vida anárquica em comunidade, cara aos seus frequentadores. Fotos e documentos revelam, por outro lado, que ele estava integrado a certas liberdades por meio da prática do poliamor, convivendo com a esposa, Maja, e a amante, Suzanne Perrottet, de forma aberta nessa comunidade. Essa atitude produziu uma situação que Preston-Dunlop considera definidora dos rumos da dança moderna alemã, na medida em que Wigman, tão reconhecida por seu talento artístico, não seduziu o homem Laban nesse contexto. Preston-Dunlop chega a afirmar que a exclusão de Wigman do círculo amoroso de Laban a faz decidir tornar-se tão ou mais relevante do que seu mestre na cena da dança.

Nesse contexto comunitário, Laban desenvolveu criações ritualizadas, em que as experiências com as energias espirituais eram protagonistas. Eugenia Casini Ropa (2014) descreve em detalhes três cenas da performance Festa do Sol, assistida por participantes do Congresso Cooperativo Anacional da Confraternidade dos lluminados Herméticos, da ordem do Templo do Oriente, no verão de 1907: O Sol Poente, Os Demônios da Noite e O Sol Vitorioso. Com atuação de alunos da escola-colônia de dança de Rudolf Laban, a cena iniciava, em tempo real, momentos antes do pôr do sol, e terminava ao amanhecer, atravessando a noite e tomando a geografia do local como cenografia natural do ritual, composto por canto, dança e oratória.
Entre os últimos anos do século XIX e os primeiros do século XX, formou-se, aos poucos, uma estância turística especial nas colinas de Ascona, pequena cidade de clima ameno, recomendada pela qualidade do ar, e pelos banhos de sol, aos doentes respiratórios e escolhida por artistas e pensadores por seu panorama. Criada por iniciativa de um casal de ex-doentes e seus amigos entusiastas, ganha vida uma espécie de colônia-sanatório, onde os fundadores se propunham a implantar um laboratório experimental de uma completa reforma da vida (Lebensreform). Liberados das restrições sociais, do assédio das cidades e do progresso tecnológico, os hóspedes imergiam, segundo os princípios mais rigorosos da Lebensreform, em um consciente retorno à natureza, cujas manifestações mais imediatas e visíveis (e amplamente divulgadas) eram o vegetarianismo e o nudismo, mas cujas repercussões profundas de caráter filosófico, psicológico e ideológico iam muito além destes comportamentos exteriores. (ROPA, 2014, p. 18).

A escola-colônia do Monte Veritá em Ascona não parece nada distante de nós, um século depois, com sua proposta de comunidade ecológica e anárquica (que hoje seria ecossomática ${ }^{12}$ ), real e metafórica: havia alimentação vegetariana, cultivo de uma produção orgânica e de ideias semeadas entre seus frequentadores, colocadas em prática por meio de diferentes atividades artístico-intelectuais. Mesmo quando não estavam presentes, cultivavam a partilha de suas experiências por meio de cartas. A relação corpo-ambiente pode ser vista em fotos em que Laban e seus alunos praticam naturismo, dançando junto à natureza.

É grande a relação de nomes dos frequentadores de suas oficinas de verão, mas, entre eles, segundo Bradley (2009, p. 11), na primeira turma estavam: a bailarina Mary Wigman (colaboradora de Laban), Kathe Wulff (artista visual), Sophie

12 Ecossomática advém da aproximação das abordagens somáticas emergentes ao campo da dança contemporânea a uma perspectiva ecologicamente centrada. A aproximação de trabalhos de dança às questões ambientais reforça a ligação entre dança, somática e ecologia, sendo o que muitos hoje estão chamando de ecossomática. 
Tauber (pintora que mais tarde casou-se com Jean Arp, um artista dadaísta), Laura Oesterreich (bailarina de formação), Maja Lederer (cantora, esposa de Laban), Suzanne Perrottet (sua amante, ex-aluna de Dalcroze) e Betty Baaron Samao (jovem aprendiz). Dessas experiências emergiu o que veio a ser conhecido como movimento coral, um movimento de grupo que une espontaneidade e desenho espacial bem definido. "Era produzido contemporaneamente com danças folclóricas particulares, com contribuições de cada indivíduo e um senso comunitário de identidade" (BRADLEY, 2009, p. 11).

A segunda turma do curso chegou com muitos projetos para desenvolver a tríade que Laban apresentava - de Dança, Tom, Palavra (Tanz-Ton-Wort $)^{13}$-, mas a declaração da Primeira Guerra Mundial foi devastadora para esse processo, levando integrantes da comunidade a viverem em condições de reformulação geopolítica e, simultaneamente, de nacionalismo extremo.

Laban circulou, em algum verão durante a resistência, entre Munique, Zurique e Ascona, e nesse período iniciou seus próprios estudos em notação de movimento. Assumia o abandono da música, tornando a dança independente, e o mesmo aconteceu com Wigman, que rompeu com sua formação na Eurítmica de Émile Jaques-Dalcroze, que tornava o movimento dependente do estímulo sonoro-rítmico. Foi também nessa época que Laban e Wigman trabalharam juntos na formulação de um programa de aulas e de um currículo de treinamento para dança segundo suas propostas. Desenvolveram teorias baseadas na Corêutica/Harmonia Espacial e na Eukinética/Expressividade/Esforço/Ímpetos ${ }^{14}$, com o objetivo de tornar o movimento significativo para além dos passos da dança (BRADLEY, 2009).

13 Dança, Tom, Palavra produz o movimento em toda a plenitude do corpo, incluindo voz e pensamento. Essa tríade evidencia a proposta multidisciplinar de Laban para a dança, ao mesmo tempo em que encoraja todas as pessoas a desenvolverem habilidades de dança não restritas às técnicas específicas e consagradas.

14 Vide nota 9.
Juntos eles estratificaram o embasamento para uma nova abordagem para a dança moderna; uma que era mais expressiva da Mãe Natureza e da natureza humana, que abraçava o exterior e o interior terreno e continha os fundamentos do movimento: mudança, troca, e adaptação das tensões. [...] Seu primeiro livro busca articular sua abordagem à dança com base em teoria, prática, experimentações, comunidade e acesso aos elementos básicos considerando a dança como uma forma de arte nela mesma e fora dela. (BRADLEY, 2009, p. 12).

Karen Bradley entrevistou Evelyn Dorr em 2004, onde encontrou algumas pistas sobre a atividade de Laban durante a primeira guerra: "Ela disse que Laban parecia estar desenvolvendo um modo novo e sistemático de pesquisar unidade na natureza e lugar do homem no universo, através do estudo e da prática de dança" (DORR apud BRADLEY, 2009, p. 13). Os campos de pesquisa, relatados por Dorr, a que Laban estava recorrendo eram vastos e labirínticos: etnologia, psicologia, fisiologia, folclore, pesquisa, filosofia, além da busca pelas representações simbólicas em diferentes manifestações religiosas, tais como símbolos para a libido e arquétipos. Aproximava-se assim, segundo essa fonte, de teorias darwinistas e junguianas em seu vasto escopo de zonas de interesse. Em sua notação, "ele tentava capturar a verdadeira natureza da transformação" (BRADLEY, 2009, p. 13).

No pós-guerra, Laban se aproximou dos dadaístas, mas, segundo Dorr (apud BRADLEY, 2009, p.14), "ele rompeu regras, foi liberal, positivista [...], muito mais ligado à reforma do que ao niilismo". Seu fascínio por uma organização psicofísica do corpo em movimento, que ele via ser relacionada à ligação entre ritmo e espaço, capturou-o ao produzir reflexões sobre as tensões e pulsões espaciais fora do eixo vertical.

Ao final da Primeira Guerra, já era pai de oito crianças, distribuídas por três cidades diferentes. Em 1918, foi acometido pela Gripe Espanhola Influenza, tornando mais difícil seu estilo de vida e sua condição financeira, situação que perdurou por aproximadamente um ano. Hospitalizado com 
frequência, e sem condições de dar andamento ao seu trabalho, Laban negociou sua escola com Suzy Perrottet e Kathe Wulff, e deixou Mary Wigman com o trabalho artístico e profissional. Estava sem teto, sem emprego fixo e prestes a terminar o casamento com Maja ao conhecer uma dançarina russa, Dussia Bereska, em 1919. Desde a morte de sua primeira esposa, era acometido por doenças intestinais e crises de depressão, com as quais ele gradualmente aprendeu a lidar, ainda que fosse voluntariamente indo a hospitais e locais de cura - que frequentemente eram relacionados à arte.

\section{Estado estável}

Os anos 1920 trouxeram a possibilidade da publicação de seus escritos realizados desde a Primeira Guerra, sobretudo quando permaneceu com uma condição mais estável em Stuttgard, onde encontrou emprego. Transitando de forma mais fluida entre a arte e a pesquisa, ele fez circular uma roda de campos de interesse entre a ciência, a filosofia, a religião e a arte. Em 1921, se tornou Ballet Master do Teatro Nacional de Mannheim, criando muitos trabalhos como Die Geblendeten, Epische Tanzfolge e Orgy of Tannhauser, de W. Richard Wagner (18131883). Mesmo estabelecido no Teatro Nacional, ele ainda não era facilmente compreendido e precisava treinar seus dançarinos profissionais de acordo com seus propósitos. Uma de suas estratégias era criar a partir de temas míticos. Ele não costumava juntar as danças corais, frequentemente feitas com fins participativos e inclusivos, com as danças teatrais, feitas para públicos específicos. Mas, eventualmente, ele agrupava essas duas frentes, tanto para fins econômicos (já que os dançarinos corais eram amadores), quanto para realizar cenas entre um coro e os principais do grupo de câmara (BRADLEY, 2009, p. 18).

Da articulação profícua entre o modo mais espontâneo das danças corais, e a condução mais estrita nos grupos de câmara, emergiu a criação de peças de dança-teatro, pela observação dos modos de aprendizagem, experimentação e apresentação de seus alunos. Laban tinha especial interesse na fase da experimentação, mas afirmava que ela é uma fase, e que a apresentação deve conter essa fase em sua forma mais fiel. Seu grupo dos anos 1920, segundo Bradley (2009), foi composto por sua nova companheira Dussia Bereska, Kurt Jooss, Herta Feig, Jens Keith, Edgar Frank e Albrecht Knust. "Alguns dos títulos das obras realizadas nesse período são The Fool's Mirror, The Crystal, Orchidee, The Magic Garden, The Earth e The Titan, que reforçam as preocupações sociopolíticas, ambientais, míticas e mágicas de Rudolf Laban" (BRADLEY, 2009, p. 20).

Em 1926, sua carreira como dançarino foi encerrada por um acidente ocorrido no grand finale de sua bem sucedida obra Don Juan, que lesionou gravemente sua coluna: ao ser lançado ao 'fogo do inferno', para fora do palco, um colchão deveria esperar sua queda fora de cena. Ao que parece, não se conhece uma versão definitiva sobre o que aconteceu. Os relatos são poucos e divididos sobre o que pode ter ocorrido naquela apresentação. Apesar disso, obteve uma crítica exuberante por esse trabalho, em que toda a sua trajetória foi reconhecida por suas inovações, fazendo dele uma grande celebridade. Sua atividade artística seguiu intensa, estabelecendo seu Instituto coreográfico que, em 1927, muda para Berlim, e em 1928 para Essen. Em 1928, funda a revista Schrifttanz, destinada a discutir a escrita da dança.

Em torno dos anos 1930, Laban dedicou-se mais à produção teórica de suas proposições. Suas reflexões o levaram a inferir sobre a carência do trabalho corporal e espiritual no teatro, apontando a inexistência e necessidade de um diretor de movimento no meio teatral. Como crítico do trabalho solo de dançarinos e suas improvisações, defendia os estudos da harmonia espacial e a notação em dança, buscando equivalência com a partitura musical, no sentido de possibilitar que diferentes dançarinos possam dançar uma obra coreográfica do passado. Ele também acreditava que, com o aprofundamento dos estudos, dançarinos poderiam desenvolver um pensamento crítico sobre forma, contorno, intenção, e produzir seus próprios trabalhos, suscitando 
a autonomia para a prática da dança. Dessa forma, mostrava-se inquestionável seu respeito pelas diferenças, pela artesania e pelo compartilhamento em processos de criação, que hoje nos são tão caros.

\section{Laban, o onírico e o nazismo}

Os meios pelos quais ele melhor conseguiu suporte financeiro para o desenvolvimento de sua proposta, num dado momento, foram permeados por uma relação ambígua com o nazismo: sua necessidade de um trabalho bem remunerado, que o fez aceitar a direção da Ópera de Berlim e de uma companhia com toda a hierarquia tradicional e suas respectivas estrelas, em contraste com seus ideais socialistas, que podem ser verificados em sua autobiografia ou até em sua proposição das danças corais. Mas a possibilidade de ter em suas mãos bailarinos experientes para realizar seus experimentos foi tentadora, bem como a ingênua crença de que poderia seduzir os nazistas com suas ideias de dança. É assim que Bradley apresenta sua relação com o nazismo; não como alguém que colaborou com o sistema por covardia, mas por ingênua pretensão de sedução. É possível verificar outras situações de ingenuidade, como reforçam alguns depoimentos de pessoas que conviveram com ele.

Laban estava focado em temas como ser, desenvolver e decompor, morrer. Seu leitmotif e seus princípios exploravam a simetria e assimetria, dinâmicas, rebotes da sustentação, etc. Seu trabalho e valores eram contra a noção nazista de despotismo, mesmo se nem ele ou eles pudessem ver o conflito num primeiro momento. Ele seguiu o caminho da arte e do movimento humanista. (DORR, 2004 apud BRADLEY, 2009, p. 29).

Algumas noções e termos seguidamente trazidos como argumentos contra Laban, em sua relação com o nazismo, são trazidos por Bradley e suas fontes para tentar amenizar contrariedades e esclarecer como se fizeram tais enlaces. Por exemplo, ela menciona que alguns bailarinos entendiam que seu sistema de notação para difusão da dança era um plano para dominar o mundo. A 'crença no bem comum e na força comum para alcançar um objetivo maior', tão caros a Laban, também eram vistos como indícios de que ele estaria afinado ao plano nazista do domínio de uma raça, por meio do 'domínio do movimento'15 que ele buscava. Bradley argumenta que suas definições para os termos 'domínio' e 'comum' eram muito diferentes das dos nazis, uma vez que o domínio do movimento é algo que infere sobre si, sobre uma reflexão pessoal a respeito da mente, do corpo e do espírito de cada dançarino, e isso também implica um domínio do discurso sobre corpo, mente e espírito. A ideia de bem comum e força comum, para Laban, era um modo de coletivizar um movimento de individuação ${ }^{16}$, algo subjetivo que se faz em conjunto por meio da dança. Foram exatamente esses aspectos que foram identificados na preparação para os Jogos Olímpicos de 1936, quando Laban foi impedido pelos nazistas de continuar sua coreografia From the Warm Wind and the New Joy - ensaiada por vinte e dois coros de movimento (espalhados por diferentes cidades da Alemanha), e com excertos falados por atores de Assim falava Zaratustra, de Nietzsche -, pois ela não representava o ideal da raça pura.

Algumas atitudes tomadas por Laban faziam cair por terra a possibilidade de ele ter sido nazista. Como jurado de um festival de dança, ele reverteu uma premiação que sairia para um grupo alemão, contemplando, ao invés disso, todos os participantes. No ensaio da dança coral acima mencionada, ele fez um discurso:

Nós não precisamos acreditar em explicações dogmáticas, em sistemas filosóficos ou em cálculos circunstanciais para entender a força de vontade da vida que preenche nosso ser pleno. Isso incomoda a nossa condição harmônica natural se tentamos encontrar a primeira fonte, o objetivo final

15 Título de um dos seus mais conhecidos livros, primeiramente publicado sob o título The mastery of movement on stage.

16 Termo utilizado por Carl Gustav Jung, aqui apropriado ao contexto labaniano, considerando sua contemporaneidade. 
fora de nós mesmos [...]. Em que consiste a fé? O que é a essência? Acreditamos em um caminho psico-fisiológico para a saúde e a alegria e nisso buscamos o nosso meIhor funcionamento individual, bem como na vida em comunidade. A visão espiritual do mundo e a questão da conexão e comunicação com a força da vida também encontra seu ancoramento natural aqui. [...] $\mathrm{O}$ trabalho nos demanda extrema devoção e grandes esforços. Com esses esforços nós não queremos enganar ou ultrapassar ninguém, não queremos fazer uma competição e ganhar benefícios extrínsecos. Não precisamos brigar uns com os outros, ou invejar os bens do outro. Carregamos tudo o que precisamos em nós mesmos. (LABAN apud BRADLEY, 2009, p. 32).

Goebels, o Ministro da Cultura nazista, assistiu ao ensaio e ao discurso, assim como, possivelmente, o próprio Hitler. Goebels escreveu em seu diário: "Tudo está vestido com as nossas roupas e não tem absolutamente nada a ver conosco" (PRESTON-DUNLOP, 1998, p. 196).

Ainda assim, é sabido que Laban colaborou com o sistema em alguma medida; o que não se sabe é se foi por coerção, ingenuidade ou concordância, o que soa muito confuso a todos pelo tempo prolongado em que ele se manteve na direção do teatro.

Mas, ao ser desligado da preparação coreográfica dos Jogos Olímpicos de Berlim, em 1936, Laban retornou a um período de paradeiro incerto e doente até chegar, em 1937, à Inglaterra e, por intermédio de seu ex-aluno Kurt Jooss ${ }^{17}$, a Dartington Hall. O lugar era uma antiga propriedade da coroa britânica, de arquitetura medieval, que estava abandonada e que foi adquirida por um casal incomum, Dorothy e Leonard Elmhirst, reunindo a riqueza da norte-americana Dorothy e a visão idealista de Leonard, britânico que estudava educação progressiva

17 Kurt Jooss foi um aluno e bailarino de Laban que posteriormente construiu sua própria companhia, destacando-se internacionalmente com a coreografia A Mesa Verde - interpretada como prenúncio da Segunda Guerra Mundial. Nessa época, exilou-se com sua companhia na Inglaterra onde, mais tarde, acolheu Laban. Jooss foi fundador da Folkwang Schule, onde foi professor e coreógrafo de Pina Bausch. e reconstrução rural. Foi também um refúgio para muitos artistas: abrigou, entre tantos outros, Ravi Shankar, Igor Stravinsky e John Cage. Naquele ambiente, Laban conheceu Lisa Ullmann, uma aluna de Jooss que passou a cuidar dele e de seu legado, reconectando-o com o mundo (BRADLEY, 2009).

\section{Impulso visual - o futuro do legado}

Laban não quis mais envolver-se com quaisquer formas de cultos, mas mover tais ideias a partir de reflexões sobre a relação do corpo com a gravidade, por meio do estudo dos sólidos platônicos ${ }^{18}$ e suas inclinações.

Ele começou a escrever e falar sobre tensões e trações espaciais que vivem dentro de formas cristalinas e descobrir modos multidimensionais em que o corpo humano pode transcender a gravidade e adquirir uma harmonia apimentada com a natureza, onde ambiente e o ser movente associam-se responsável e ativamente. (BRADLEY, 2009, p. 34).

Quando a Segunda Guerra chegou a Dartington, todos foram obrigados a se retirar. Lisa e Laban foram alocados para uma fazenda na zona rural de Wales pelo casal hospedeiro, os Elmhirsts.

F.C. Lawrence era um consultor de gestão
quando Leonard Elmhirst apresentou-o a
Laban. Durante a Segunda Guerra Mundial,
Lawrence e Laban combinaram as aborda-
gens tradicionais dos estudos sobre tempo-
-moção com a eficiência de trabalhadores,
por meio da análise de Laban em esforço
e espaço. Observando mulheres jovens
lançarem grandes pneus e peças de equi-

18 Os sólidos platônicos descritos por Platão em, aproximadamente, 400 a.C., são sólidos convexos cujas arestas formam polígonos planos regulares congruentes. Os sólidos platônicos são apenas cinco, mas, a partir da contiguidade das arestas de um triângulo equilátero, por exemplo, podemos construir um tetraedro, um octaedro ou um icosaedro; das arestas de um quadrado equilátero, podemos construir um cubo; de um pentágono, podemos construir um dodecaedro. Essa sabedoria foi utilizada em formas arquitetônicas seculares e, sendo eles apenas cinco, formou também bases místicas para muitas filosofias e crenças. 
pamentos para esforço de guerra, deu-lhes oportunidade de observar o papel do estilo pessoal na eficiência. Tipo físico e predileções por permutas particulares de expressão e trajetórias cumpriam um papel na produtividade e na satisfação com o trabalho de mulheres contratadas em lugar dos homens que deixaram seus empregos pela guerra. Laban e Lawrence nomearam sua abordagem 'cadência no trabalho' e isso revolucionou a indústria. (BRADLEY, 2009, p. 35).

Além da formação e da colaboração com Lawrence, Laban também formou e desenvolveu colaboração com Valerie Preston-Dunlop, Warren Lamb e Marion North, após abrir seu estúdio da Arte do Movimento em 1946, em parceria com Lisa Ullmann e com suporte financeiro do casal Elmhirst, em Manchester. Associando a análise de movimento de Laban com a psicologia, Marion North elaborou sua pesquisa de acesso à personalidade por meio do movimento. Warren Lamb desenvolveu seu Perfil de Movimento e uma análise de padrões de movimento, que abordava estilos de tomadas de decisão no meio da gestão e planejamento em indústrias.

Irmgard Bartenieff (1900-1981) iniciou seus estudos com Laban em 1925 e formou sua companhia de dança articulando saberes. Em meados dos anos 1950 ela vai à Inglaterra seguir estudos sazonais por cinco anos consecutivos enquanto dá início à prática com princípios geradores dos Fundamentos de Bartenieff (BF), já residente em Nova lorque. Em 1973 forma a primeira turma de seu programa de certificação em Laban Movement Studies LMS, conferindo aos estudantes o Certificado de Analista de Movimento (CMA). Mais tarde o LMS recebe seu nome ao lado do de Laban, constituindo um dos grandes centros de formação internacional deste legado.

\section{Labirinto móvel e multidimensional}

Esse texto apresenta alguns rastros dos movimentos da vida de Laban e suas circularidades, mostrando um labirinto em movimento (como as imagens de Escher) que nos permite encontrar várias perspectivas para as assinaturas de movimento labanianas. Seu propósito foi pulverizado pela semeadura da cultura festiva entre seus pares, horizontalizando autorias, mesmo quando se via apartado de seus pulpilos e por eles superado. Se Laban não desfrutou de todas as portas abertas de seu labirinto relacional, indicou os caminhos aos seguidores, que, honrando seu nome e trajetória, atualizam esse legado em infinitos e sofisticados desdobramentos.

Seu temor pelo domínio das máquinas não afastou seu material de aparatos de estudo eletrônicos, como o vídeo e os programas de computação digital para a escrita iconográfica. Hoje já temos programas para a utilização digital da labanotação, e aplicativos interativos para a aprendizagem da mesma.

Se a vida é um labirinto interativo e nela desenvolvemos um corpo vivo relacional, inventamos e reinventamos percursos, para um constante retorno a si mesmo, mesmo que em outros tempos, espaços ou corpos.

\section{Referências}

ADAMS, Marcelo, CARDOSO, Tatiana, MODINGER, Carlos, SASTRE, Cibele. Propostas de uma escrita Transcriativa. In: ICLE, Gilberto. (org). Descrever o inapreensível. São Paulo: Perspectiva, 2019.

BRADLEY, Karen, K. Rudolf Laban. New York: Routledge performers practitioners, 2009.

DELEUZE, Gilles. Diferença e Repetição. São Paulo: Graal, 2006.

DOCZI, Gyorgy. The Power of Limits: Proportional Harmonies in Nature, Art, and Architecture. Boston: Shambala, 1994.

FERNANDES, Ciane. O Corpo em Movimento: O sistema Laban/Bartenieff na formação e pesquisa em Artes Cênicas. São Paulo: Annablume, 2006.

MIRANDA, Regina. Corpo Espaço: Aspectos de uma geofilosofia do movimento. Rio de Janeiro: 7 letras, 2008. 
PRESTON-DUNLOP, Valerie. Rudolf Laban: An Extraordinary Life. London: Dance Books, 1998.

ROPA, Eugenia Casini. A Dança e o Agit-Prop: Os teatros não teatrais na cultura alemã no início do século XX. São Paulo: Perspectiva, 2014.

TAPIA, Marcelo; NOBREGA, Thelma Médici. Haroldo de Campos - Transcriação. São Paulo: Perspectiva, 2013.

Recebido: $26 / 06 / 2020$

Aceito: $28 / 09 / 2020$

Aprovado para publicação: 08/12/2020

Este é um artigo de acesso aberto distribuído sob os termos de uma Licença Creative Commons Atribuição 4.0 Internacional. Disponível em: <http://creative commons.org/licenses/by/4.0>.

This is an open-access article distributed under the terms of the Creative Commons Attribution License 4.0 International. Available at: <http://creative commons.org/licenses/by/4.0>.

Ce texte en libre accès est placé sous licence Creative Commons Attribution 4.0 International. Disponible sur: <http://creativecommons.org/licenses/by/4.0>. 